LITERATUR REVIEW

\title{
ANEMIA DALAM KEHAMILAN DENGAN KEJADIAN PERDARAHAN POST PARTUM
}

\section{Hesteria Friska Armynia Subratha}

\author{
Program Studi D3 Kebidanan Fakultas Kedokteran Universitas Pendidikan Ganesha \\ (hesteria.friska@gmail.com, 08980729733)
}

\begin{abstract}
ABSTRAK
Pendahuluan : Beberapa penelitian menunjukkan bahwa anemia pada ibu hamil dapat menyebabkan terjadinya perdarahan post partum. Perdarahan post partum merupakan salah satu penyebab kematian ibu. Tujuan : Tujuan dari literature review adalah untuk mereview faktor hubungan anemia dalam kehamilan dengan kejadian perdarahan post partum. Metode : Literatur review dilakukan berdasarkan issue, metodologi, persamaan dan proposal penelitian lanjutan. Dari 5 penelitian yang digunakan menggunakan metode penelitian kuantitatif. Populasinya adalah ibu hamil. Hasil : Berdasarkan 5 penelitian didapatkan bahwa ada hubungan antara anemia pada kehamilan dengan perdarahan post partum. Kesimpulan : Disarankan kepada ibu hamil untuk melakukan pemeriksaan kehamilan sesuai standar pemeriksaan kehamilan dan melakukan pemeriksaan $\mathrm{Hb}$ serta mengkonsumsi tablet $\mathrm{Fe}$ sebagai deteksi dini anemia dalam kehamilan dan pencegahan perdarahan post partum.
\end{abstract}

Kata kunci : Anemia, perdarahan post partum, kehamilan

\begin{abstract}
Introduction : Several studies have shown that anemia in pregnant women can cause postpartum hemorrhage. Post partum haemorrhage is the one of maternal death. Objective: The purpose of the literature review is to review the relationship factors of anemia in pregnancy with the incidence of postpartum hemorrhage. Methods: Literature review is carried out based on issues, methodologies, similarities and further research proposals. Of the 5 studies used quantitative research methods. The population is pregnant women. Results: Based on 5 studies, it was found that there was a relationship between anemia in pregnancy and postpartum hemorrhage. Conclusion: It is advisable for pregnant women to antenatal appropriate standard pregnancy tests and checks $\mathrm{Hb}$ and consuming Fe tablet as early detection of anemia in pregnancy and the prevention of postpartum hemorrhage.
\end{abstract}

Keywords : Anemia, postpartum hemorrhage, pregnancy

\section{PENDAHULUAN}

Angka Kematian Ibu (AKI) merupakan salah satu indikator yang dapat menggambarkan kesejahteraan masyarakat di suatu negara. AKI di dunia pada tahun 2015 menurut data World Health Organization (WHO) adalah sebanyak 216 per 100.000 kelahiran hidup atau diperkirakan jumlah kematian ibu yaitu sebesar 302.000 kematian.

Di negara berkembang jumlah AKI 20 kali lebih tinggi dibandingkan AKI di negara maju yaitu sekitar 239 per 100.000 kelahiran hidup, sedangkan di negara 
maju hanya 12 per 100.000 kelahiran hidup pada tahun 2015. Menurut Rafikasari, 2017, Angka Kematian Ibu (AKI) di Indonesia pada tahun 2016 masih sangat tinggi yaitu mencapai 359 per 100.000 kelahiran hidup, angka tersebut menduduki peringkat pertama di Asia Tenggara (WHO, 2016).

Pada tahun 2017, berdasarkan data Profil Kesehatan Provinsi Bali, jumlah AKI sebesar 68,6 per 100.000 kelahiran hidup. Angka tersebut masih berada di bawah angka nasional yaitu 95 per 100.000 kelahiran hidup. Di Kabupaten Buleleng, jumlah AKI pada tahun 2017 sudah berhasil ditekan hingga menjadi 83 per 100.000 kelahiran hidup. Namun, jika dilihat dari jumlah absolut kematian ibu per kabupaten atau kota, kasus kematian ibu di Kabupaten Buleleng masih berada pada posisi pertama di Provinsi Bali dan AKI di Kabupaten Buleleng lebih besar dibandingkan AKI di Provinsi Bali yaitu sebesar 14,4 per 100.000 kelahiran hidup. Meskipun pada tahun 2017 di Kabupaten Buleleng hanya di temukan 9 kasus kematian ibu, namun hal ini merupakan angka tertinggi di Provinsi Bali. Berdasarkan data Profil Kesehatan Indonesia tahun 2017 didapatkan kasus angka kematian ibu (AKI) sebesar 1712 kasus, yang terbanyak disebabkan oleh karena anemia saat hamil dan juga perdarahan, sedangkan data AKI di Bali tahun 2016 sebesar 70,5 per 100.000 KH (Kelahiran Hidup) yang mengalami peningkatan menjadi 83,4 per $100.000 \mathrm{KH}$ di tahun 2017 (Profil Dinas Kesehatan Provinsi Bali, 2017).

Anemia adalah suatu keadaan dimana tubuh memiliki jumlah sel darah merah (eritrosit) yang terlalu sedikit, yang mana sel darah merah mengandung hemoglobin yang berfungsi untuk membawa oksigen ke seluruh jaringan tubuh. Kadar hemoglobin $(\mathrm{Hb})$ ibu hamil dikatakan anemia jika $\mathrm{Hb}<11$ g/dL. WHO (2008) mengungkapkan, secara global prevalensi anemia pada ibu hamil di seluruh dunia adalah sebesar $41,8 \%$. Prevalensi anemia pada ibu hamil di Asia sebesar 48,2\%. Menurut hasil pengamatan Simanjuntak, mengungkapkan bahwa sekitar 70\% ibu hamil di Indonesia menderita anemia kekurangan gizi dan kebanyakan anemia yang diderita oleh masyarakat salah satunya karena kehamilan dan persalinan dengan jarak yang berdekatan, ibu hamil dengan pendidikan dan tingkat sosial ekonomi yang rendah. Ibu hamil yang menderita anemia memiliki kemungkinan akan mengalami pendarahan post partum. Perdarahan post partum adalah perdarahan yang terjadi pada pasca persalinan yang jumlahnya melebihi $500 \mathrm{cc}$.

(Depkes, 2015) membuktikan bahwa keberhasilan pembangunan dalam bidang kesehatan dapat dilihat dari tinggi rendahnya angka kematian ibu. Menurut World Health Organization (WHO) tahun 2015, diperkirakan kematian ibu sebesar 303.000 jiwa atau sekitar 216/100.000 kelahiran hidup di seluruh dunia. Kematian ibu di negara berkembang berkaitan dengan anemia pada kehamilan 
disebabkan oleh defisiensi besi dan perdarahan akut. Sekitar 35\% - 75\% ibu hamil mengalami defisiensi besi dan hal ini semakin meningkat seiring dengan bertambahnya usia kehamilan. Menurut hasil survey SDKI tahun 2012, di Indonesia angka kematian ibu mencapai 359 kematian per 100.000 kelahiran hidup. Jumlah ini meningkat dibandingkan data SDKI 2007 sebesar 228 kematian dan masih merupakan tertinggi di Asia. Angka kejadian ibu hamil dengan anemia menurut (Depkes, tahun 2015) yaitu sebesar $37,1 \%$.

\section{METODE PENELITIAN}

Jurnal yang digunakan dalam literature review didapatkan melalui database penyedia jurnal international Proquest dan jurnal Scientific Indonesia melalui google scholar. Penulis membuka website www.Search.Proquest.com dan www.googlescholar.com Peneliti menuliskan kata kunci sesuai MESH (Medical Subject Heading) yaitu "anemia", "perdarahan", dan "post partum" dan dipilih full text. Muncul 25.414 temuan, kemudian dipersempit dengan yang dissertation and theses dan ditemukan 9.275 temuan selanjutnya diurutkan dari yang terbaru. Mengenai pemilihan Bahasa tidak dilakukan karena semuanya jurnal yang ditemukan telah menggunakan bahasa inggris. Demikian juga untuk google scholar didapatkan 1507 temuan kemudian dispesifikan dalam 6 tahun terakhir dan didapatkan sebanyak 687 temuan. Setiap pertanyaan tersebut telah mengikuti PICOT dimana setiap pertanyaan terdapat $\mathrm{P}=$ problem/ pasien/ populasi, $\mathrm{I} / \mathrm{E}=$ implementasi/intervensi/exposure, $\quad \mathrm{C}=$ kontrol/ intervensi pembanding, $\mathrm{O}=$ hasil dan $\mathrm{T}=$ Time.

Hal lain yang relevan yang penulis gunakan dalam mendapatkan jurnal tentang hubungan anemia dalam kehamilan dengan kejadian perdarahan post partum. Penulis mengambil semua desain penelitian yang digunakan dalam mengidentifikasi hubungan anemia dalam kehamilan dengan kejadian perdarahan post partum.

\section{HASIL DAN PEMBAHASAN}

Hasil literature reriew disajikan pada table 1. 
Tabel 1. Tabel Literature Review

\begin{tabular}{|c|c|c|c|c|c|c|}
\hline No & Penulis & Judul & Desain & Responden & $\begin{array}{l}\text { Prosedur } \\
\text { Penilaian }\end{array}$ & Hasil \\
\hline 1. & $\begin{array}{l}\text { Sofia, } \\
\text { D. } \\
\text { (2015). }\end{array}$ & $\begin{array}{l}\text { Hubungan } \\
\text { Anemia } \\
\text { Dalam } \\
\text { Kehamilan } \\
\text { Dengan } \\
\text { Perdarahan } \\
\text { Post Partum }\end{array}$ & $\begin{array}{l}\text { Cross } \\
\text { sectional }\end{array}$ & $\begin{array}{l}\text { Keseluruha } \\
\mathrm{n} \text { dijadikan } \\
\text { sampel } \\
\text { (total } \\
\text { population) } \\
\text { sebanyak } \\
25 \text { orang. }\end{array}$ & 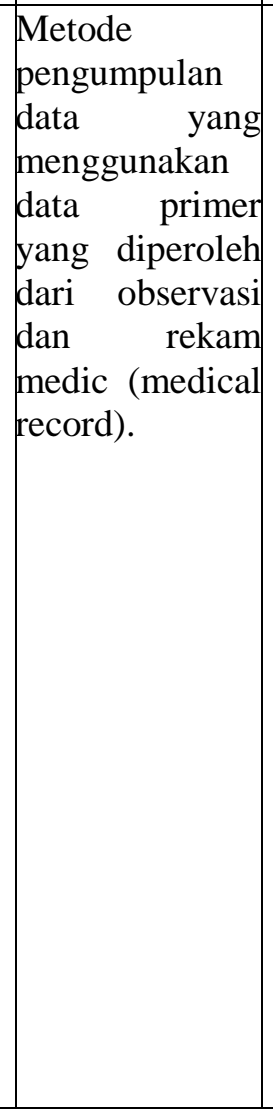 & $\begin{array}{l}\text { Pada Penelitian } \\
\text { (Sofia, 2015) } \\
\text { membuktikan bahwa ada } \\
\text { hubungan antara anemia } \\
\text { pada kehamilan dengan } \\
\text { perdarahan post partum. } \\
\text { Hal ini dibuktikan dari } \\
\text { hasil Uji Analisis Statistic } \\
\text { Koefsien Kontingensi } \\
\text { ditunjukkan bahwa pada } \\
\text { kolom Approx. sig } \\
\text { didapatkan nilai lebih } \\
\text { kecil dari level of } \\
\text { significant a 0.05 ( p< } \\
\text { 0.05) yaitu (0,008<0,05). } \\
\text { Maka dengan demikian } \\
\text { dapat disimpulkan bahwa } \\
\text { H0 ditolak dan H1 } \\
\text { diterima. Berarti ada } \\
\text { hubungan yang signifikan } \\
\text { antara anemia pada } \\
\text { kehamilan dengan } \\
\text { perdarahan post partum di } \\
\text { RSUD Asembagus pada } \\
\text { tahun 2014. }\end{array}$ \\
\hline 2. & $\begin{array}{l}\text { Feny, A. } \\
\text { (2017) }\end{array}$ & $\begin{array}{l}\text { Hubungan } \\
\text { Anemia Pada } \\
\text { Saat } \\
\text { Kehamilan } \\
\text { Dengan } \\
\text { Kejadian } \\
\text { Perdarahan } \\
\text { Postpartum } \\
\text { Di RSUD } \\
\text { Panembahan } \\
\text { Senopati } \\
\text { Bantul }\end{array}$ & $\begin{array}{l}\text { Case } \\
\text { control }\end{array}$ & $\begin{array}{l}\text { Sampel } \\
\text { penelitian } \\
\text { kelompok } \\
\text { kasus } \\
\text { sejumlah } \\
64 \\
\text { responden } \\
\text { dan } \\
\text { kelompok } \\
\text { kontrol } \\
\text { sebanyak } \\
64 \\
\text { responden }\end{array}$ & \begin{tabular}{|l} 
Metode \\
penelitian ini \\
menggunakan \\
metode survei \\
analitik case \\
control dengan \\
pendekatan \\
retrospective
\end{tabular} & $\begin{array}{l}\text { Anemia pada ibu hamil } \\
\text { merupakan masalah } \\
\text { kesehatan terkait dengan } \\
\text { insiden yang tinggi dan } \\
\text { komplikasi dapat timbul } \\
\text { baik pada ibu maupun } \\
\text { pada janin. Lebih dari } \\
50 \% \text { ibu hamil dengan } \\
\text { anemia, dan meyebabkan } \\
\text { kesakitan dan kematian } \\
\text { ibu hamil }\end{array}$ \\
\hline 3. & $\begin{array}{l}\text { Aisyah, } \\
\text { J. } \\
\text { (2017). }\end{array}$ & $\begin{array}{l}\text { Kejadian } \\
\text { Anemia pada } \\
\text { Ibu Hamil } \\
\text { Ditinjau dari } \\
\text { Paritas dan } \\
\text { Usia. } \\
\end{array}$ & $\begin{array}{l}\text { cross } \\
\text { sectional }\end{array}$ & $\begin{array}{l}\text { Didapatkan } \\
\text { sampel } \\
\text { berjumblah } \\
277 \text { orang }\end{array}$ & $\begin{array}{l}\text { Analisis data } \\
\text { menggunaka } \\
\mathrm{n} \text { uji statistic } \\
\text { chi-square }\end{array}$ & $\begin{array}{l}\text { Adanya korelasi antara } \\
\text { kejadian anemia pada ibu } \\
\text { hamil dengan paritas (p } \\
\text { value } 0,023 \text { ) dan usia (p } \\
\text { value } 0,028)\end{array}$ \\
\hline 4. & $\begin{array}{l}\text { Satriyan } \\
\text { dari, Y., } \\
\& \\
\text { Hariyati, } \\
\text { N. R. R. } \\
(2017) .\end{array}$ & $\begin{array}{l}\text { Faktor- } \\
\text { Faktor Yang } \\
\text { Mempengaru } \\
\text { hi } \\
\text { Perdarahan } \\
\text { Post Partum }\end{array}$ & $\begin{array}{l}\text { case } \\
\text { control }\end{array}$ & $\begin{array}{l}\text { Sampel } 80 \\
\text { dengan } 40 \\
\text { sampel } \\
\text { kasus dan } \\
40 \text { sampel } \\
\text { kontrol. }\end{array}$ & $\begin{array}{l}\text { Analisis } \\
\text { bivariate } \\
\text { Chi-Square, } \\
\text { dan analisis } \\
\text { multivariat } \\
\text { Regresi }\end{array}$ & $\begin{array}{l}\text { Hasil analisis bivariat } \\
\text { terdapat tiga variabel } \\
\text { yang memiliki hubungan } \\
\text { dengan perdarahan } \\
\text { postpartum yaitu paritas } \\
\text { (b-value }=0,042 \text {, }\end{array}$ \\
\hline
\end{tabular}




\begin{tabular}{|c|c|c|c|c|c|c|}
\hline & & & & & $\begin{array}{l}\text { logistik } \\
\text { berganda. }\end{array}$ & 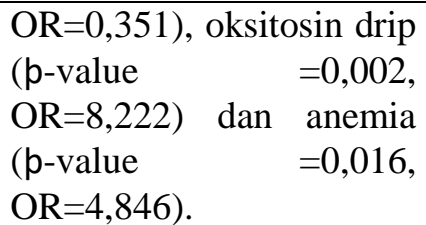 \\
\hline 5. & $\begin{array}{l}\text { Fras, K. } \\
\text { A. } \\
(2015)\end{array}$ & $\begin{array}{l}\text { Post partum } \\
\text { hemorrhage } \\
\text { is related to } \\
\text { the } \\
\text { hemoglobin } \\
\text { levels at } \\
\text { labor: } \\
\text { Observationa } \\
\text { l study. } \\
\text { Alexand ria } \\
\text { Journal of } \\
\text { Medicin e, } \\
51(4), \quad 333- \\
337\end{array}$ & $\begin{array}{l}\text { Cross } \\
\text { sectional }\end{array}$ & $\begin{array}{l}53 \text { kasus } \\
\text { wanita } \\
\text { hamil }\end{array}$ & $\begin{array}{l}\text { Sebuah studi } \\
\text { potong } \\
\text { lintang } \\
\text { dilakukan } \\
\text { antara } \\
\text { (1Agustus } \\
2012 \text { dan } 30 \\
\text { Juli 2013) di } \\
\text { Rumah Sakit } \\
\text { Umum Al } \\
\text { Thawra }\end{array}$ & $\begin{array}{l}\text { Terjadi perdarahan post } \\
\text { partum pada } 53 \text { wanita } \\
(29,1 \%) \text {. Dari } 53 \text { wanita, } \\
21 \text { kasus }(39,6 \%) \\
\text { mengalami atonia uteri } \\
\text { berat dan diperlukan } \\
\text { histerektomi darurat dan } \\
32 \text { kasus lainnya } \\
(60,37 \%) \text { menanggapi } \\
\text { conservative tindakan }(p \\
0,03) \text {. }\end{array}$ \\
\hline
\end{tabular}

Dari hasil telaah literature review didapatkan hasil bahwa ditemukan adanya hubungan antara anemia dalam kehamilan dengan kejadian perdaraha post partum. Pada Penelitian (Sofia, 2015) membuktikan bahwa ada hubungan antara anemia pada kehamilan dengan perdarahan post partum. Hal ini dibuktikan dari hasil Uji Analisis Statistic Koefsien Kontingensi ditunjukkan bahwa pada kolom Approx. sig didapatkan nilai lebih kecil dari level of significant $\alpha$ 0.05 ( $\mathrm{p}<0.05)$ yaitu $(0,008<0,05)$. Maka dengan demikian dapat disimpulkan bahwa H0 ditolak dan H1 diterima. Berarti ada hubungan yang signifikan antara anemia pada kehamilan dengan perdarahan post partum di RSUD Asembagus pada tahun 2014.

Hal ini juga memiliki kesamaan dengan penelitian Aisyah, J. (2017) yang mendapatkan hasil adanya korelasi antara kejadian anemia pada ibu hamil dengan paritas ( $p$ value 0,023 ) dan usia ( $p$ value
0,028). Hasil penelitian Satriyandari, Y., \& Hariyati, N. R. (2017) mendapatkan hasil analisis bivariat terdapat tiga variabel yang memiliki hubungan dengan perdarahan postpartum yaitu paritas ( $\mathrm{p}$-value $=0,042$, $\mathrm{OR}=0,351$ ), oksitosin drip ( $\mathrm{p}$-value $=0,002$, $\mathrm{OR}=8,222)$ dan anemia ( $p$-value $=0,016$, $\mathrm{OR}=4,846)$.

Hal yang berbeda diinformasikan oleh Feny, A. (2017) dalam penelitiannya, dimana hasil penelitian menyebutkan bahwa Anemia pada ibu hamil merupakan masalah kesehatan terkait dengan insiden yang tinggi dan komplikasi dapat timbul baik pada ibu maupun pada janin. Lebih dari 50\% ibu hamil dengan anemia, dan meyebabkan kesakitan dan kematian ibu hamil.

Hasil penelitian Fras, K. A. (2015) menunjukkan bahwa Terjadi perdarahan post partum pada 53 wanita $(29,1 \%)$. Dari 53 wanita, 21 kasus $(39,6 \%)$ mengalami atonia uteri berat dan diperlukan 
histerektomi darurat dan 32 kasus lainnya $(60,37 \%)$ menanggapi conservative tindakan $(p 0,03)$.

\section{KESIMPULAN DAN SARAN}

Berdasarkan 5 penelitian didapatkan bahwa ada hubungan antara anemia pada kehamilan dengan perdarahan post partum.

Dari hasil Literature review merekomendasikan didapatkan hasil bahwa terdapat hubungan anemia pada kehamilan dengan perdarahan post partum. Untuk itu Bidan sebagai tenaga kesehatan diharapkan memantau pemberian tablet $\mathrm{Fe}$ pada ibu hamil agar rutin dikonsumsi serta melakukan pemeriksaan kadar $\mathrm{Hb}$ ibu hamil pada trimester I dan trimester III, dan bagi ibu hamil diharapkan untuk lebih sering melakukan pemeriksaan kehamilan atau ANC(antenatal care).

\section{DAFTAR PUSTAKA}

Aisyah, J. (2017). Kejadian Anemia pada Ibu Hamil Ditinjau dari Paritas dan Usia. Jurnal Ilmu Kesehatan Vol2 No 2.

Astriana, W. (2017). Kejadian Anemia pada Ibu Hamil Ditinjau dari Paritas dan Usia. Jurnal Aisyah Vol.2 No.2.

Dewi Y., Frisca. (2019). Hubungan Anemia dengan Kejadian Perdarahan Pasca Persalinan. Jurnal Kesehatan AlIrsyad Vol.7 No.2.

Lantu, F., Aprilia. (2016). Kadar Hemoglobin (Hb) Ibu Hamil. Jurnal e-Clinic Vol.4 No.1.
Frass, K. A., (2015). Postpartum Hemorrhage is Related to the Hemoglobin Levels at Labor: Observational Studi. Alexandria Journal of Medicine. 51(4): 333-337.

Handayani, S. (2019). Kondisi Demografi Ibu dan Suami pada Kasus Kematian Ibu. Higeia. Vol. 3 No.1).

Julizar, M. (2019) Analisis Faktor Risiko Atonia Uteri. Jurnal Ilmiah Ilmu Kesehatan. Vol.7 No.3

Montufar-Rueda, C., Rodriguez, L., Jarquin, J. D., Barboza, A., Bustillo, M.C., Marin, F., Ortiz, G., \& Estrada, F. (2013). Severe Postpartum Hemorrhage from Uterine Atony: A Multicentric Study. Journal of Pregnancy. 2013: 1-7.

Riani, dkk. (2019). Hubungan Status Ekonomi dan Status Gizi dengan Kejadian Anemia pada Ibu Hamil. Jurnal Doppler Universitas Pahlawan Tuanku Tambusai. 3(2): 1-2.

Satriyandari, Y., \& Hariyati, N. R. (2017). Faktor-Faktor Yang Mempengaruhi Perdarahan Post Partum. Journal of Health Studies Vol.1 No.1.

Sofia, D. (2015). Hubungan Anemia Dalam Kehamilan Dengan Perdarahan Post Partum. Jurnal Oksitosin, Kebidanan Vol.3 No.2.

Feny, A. (2017). Hubungan Anemia Pada Saat Kehamilan Dengan Kejadian Perdarahan Postpartum Di Rsud Panembahan Senopati Bantul. Naskah Publikasi FIK Universitas Aisyiyah Yogyakarta.

Sumiati, E., (2020) Hubungan Pendarahan Post Partum dengan Anemia pada Kehamilan. Jurnal Penelitian dan Kajian Ilmiah Kesehatan Vol.6 No.2 